\title{
Computing seismic properties of natural gases and evaluating AVO responses
}

R. R. Carvalho ${ }^{1}$ and F. S. Moraes ${ }^{1,2},{ }^{1}$ Reservoir Inference Group, Universidade Estadual do Norte Fluminense, ${ }^{2}$ INCT-GP Instituto Nacional de Ciência e Tecnologia Geofísica do Petróleo

Copyright 2019, SBGf - Sociedade Brasileira de Geofísica

This paper was prepared for presentation during the $16^{\text {th }}$ International Congress of the Brazilian Geophysical Society held in Rio de Janeiro, Brazil, 19-22 August 2019.

Contents of this paper were reviewed by the Technical Committee of the $16^{\text {th }}$ International Congress of the Brazilian Geophysical Society and do not necessarily represent any position of the SBGf, its officers or members. Electronic reproduction or storage of any part of this paper for commercial purposes without the witten consent of the Brazilian Geophysical Society is prohibited.

\section{Abstract}

We investigate the performance of original and modified DASH formulations for predicting acoustic velocity in natural gases as compared to the Batzel and Wang equations. Our results demonstrate that the alternative formulations are capable of predicting acoustic velocity with better accuracy for the Starvodgass and Gulf Coast gas mixtures. It is also observed that modified DASH formulation is capable of capturing a temperature bias that the original DASH formulation is not. Furthermore, we evaluate the differences in AVO modeling observed when fluid properties are calculated with DASH and BW equations in a synthetic interface of reservoir and overlaying sealing.

\section{Introduction}

Batzle and Wang (1992) (BW) developed an important formulation of equations that allow for the determination of seismic properties in pore fluids. Carvalho and Moraes (2018) compile an alternative formulation for computing these seismic properties in natural gases, designating it as the DASH formulation, after Dranchuk and AbouKassem (1975) and Sutton and Hamman (2009). Carvalho and Moraes (2019) provide their own input into DASH formulation, developing a new equation for heat capacity ratio. This rearranged set of equations is called the modified DASH formulation, and in the same manner as BW and DASH formulations, it is implemented to estimate acoustic velocity in natural gases. In the present work, we apply the studied formulations to the Starvodgass and Gulf Coast gas mixtures in order to verify their performance for predicting acoustic velocity in the fluids. AVO modeling is also implemented in order to verify the reflectivity differences when fluid properties are calculated with BW and DASH formulations.

\section{Method}

We apply and analyze three different sets of equations for predicting acoustic velocity in natural gas mixtures: BW equations, which were developed and compiled by Batzel and Wang (1992); DASH equations, which were compiled by Carvalho and Moraes (2018) after the formulations proposed by Dranchuk and Abou-Kassem (1975) and
Sutton and Hamman (2009); and finally Modified DASH equations, which use the expression for heat capacity ratio presented by Carvalho and Moraes (2019).

The main goal of these formulations is to compute bulk modulus and acoustic velocities in natural gases. To perform such estimations, various equations are used within the formulation in order to calculate variables in the intermediate steps. These variables comprise mainly pseudo-critical temperature and pressure, z-factor, density, isothermal heat capacity, heat capacity ratio, adiabatic compressibility, and ideal heat capacity.

To test the accuracy of the formulations, we model acoustic velocity in two natural gas mixtures described by Younglove et al. (1993): Equinor (formerly Statoil) Starvodgass and Gulf Coast gas mixtures, in a total of 127 experimental data points of measured acoustic velocity at several pressure and temperature conditions. The compositions of the gas mixtures are informed on Tables 1 and 2.

Table 1 - Composition of the Gulf Coast gas mixture

\begin{tabular}{|c|c|}
\hline Component & Mol. Fraction \\
\hline $\mathrm{C} 1$ & 0.74348 \\
\hline $\mathrm{C} 2$ & 0.12005 \\
\hline $\mathrm{C} 3$ & 0.08251 \\
\hline $\mathrm{n}-\mathrm{C} 4$ & 0.03026 \\
\hline $\mathrm{n}-\mathrm{C} 5$ & 0.00575 \\
\hline $\mathrm{n}-\mathrm{C} 6$ & 0.0023 \\
\hline $\mathrm{CO} 2$ & 0.01028 \\
\hline $\mathrm{N} 2$ & 0.00537 \\
\hline
\end{tabular}

Table 2 - Composition of the Stavordgass gas mixture

\begin{tabular}{|c|c|}
\hline Component & Mol. Fraction \\
\hline C1 & 0.96561 \\
\hline C2 & 0.01829 \\
\hline C3 & 0.0041 \\
\hline n-C4 & 0.00098 \\
\hline i-C4 & 0.00098 \\
\hline n-C5 & 0.00032 \\
\hline i-C5 & 0.00046 \\
\hline n-C6 & 0.00067 \\
\hline CO2 & 0.00597 \\
\hline N2 & 0.00262 \\
\hline
\end{tabular}


Finally, we perform an AVO analysis simulating the interface of a Boise sandstone reservoir as described by Gregory (1976), with an overlaying sealing with properties as per Table 3. The reservoir is saturated with the Starvordgass gas mixture. Seismic properties of the medium saturated with the fluid are calculated using Gassman (1951). AVO responses are modeled using Zoeppritz equations (Zoeppritz, 1919) at a high-pressure (14000 psia) and high-temperature (126.85 DEG C) scenario.

Table 3 - Characteristics of the upper layer. Source: modified from Carvalho and Moraes (2018b)

\begin{tabular}{|c|c|}
\hline \multicolumn{2}{|c|}{ Characteristics of the sealing rock } \\
\hline$V p$ & $1850 \mathrm{~m} / \mathrm{s}$ \\
\hline$V s$ & $1100 \mathrm{~m} / \mathrm{s}$ \\
\hline Density & $2.28 \mathrm{~g} / \mathrm{cc}$ \\
\hline
\end{tabular}

\section{Results}

Figures $1-5$ correspond to the modeled acoustic velocity for the Gulf Coast gas mixture, at temperatures from 450 DEG R to 630 DEG R. Pressures and temperatures are expressed in their estimated reduced form.

It can be observed that DASH formulation largely outperforms the traditional BW equations in all isotherms studied. In fact, as pressure and temperature increase, DASH and modified DASH formulations tend to outperform BW formulation even more.

Furthermore, modified DASH shows relevant increase in accuracy when temperature approaches criticality (pseudo-reduced temperature near unity).

Gulf Coast Mixture Younglove et al. (1993) 450 DEG R

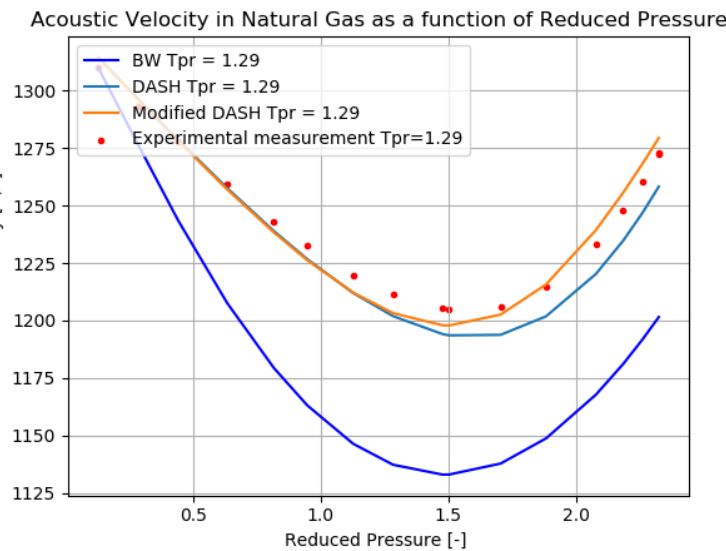

Figure 1 - Modeled and experimental acoustic velocities in the Gulf Coast natural gas mixture at 450 DEG $R$.
Gulf Coast Mixture Younglove et al. (1993) 495 DEG R

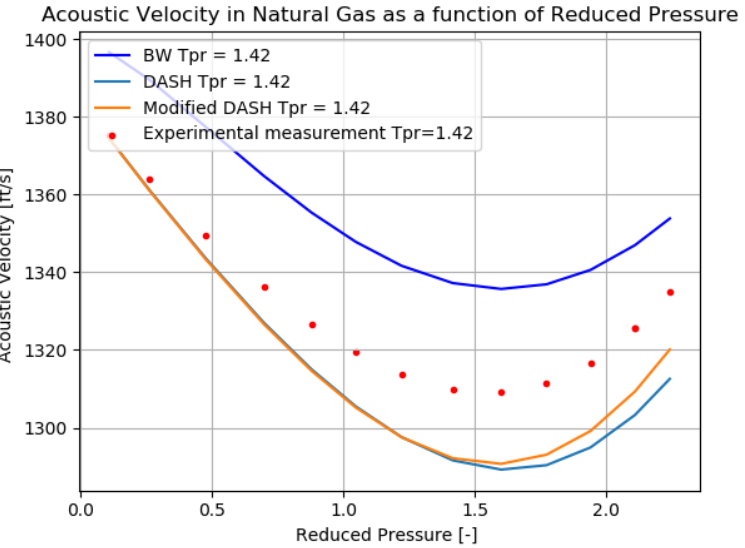

Figure 2 - Modeled and experimental acoustic velocities in the Gulf Coast natural gas mixture at 495 DEG R.

Gulf Coast Mixture Younglove et al. (1993) 540 DEG R

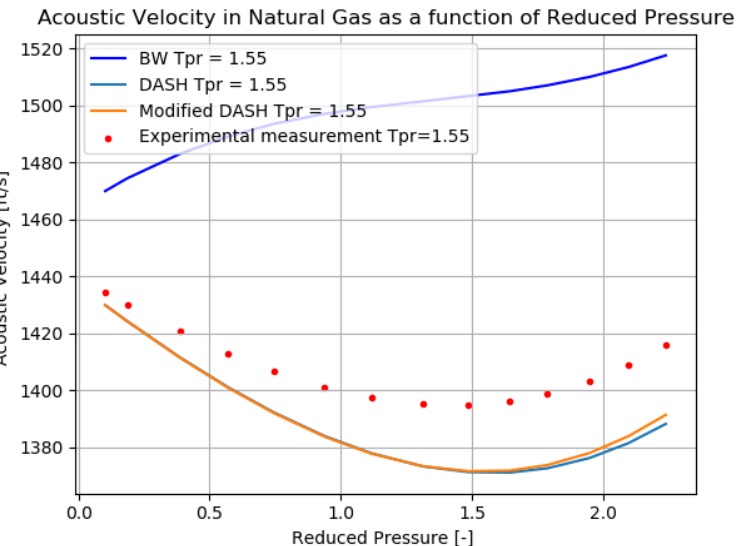

Figure 3 - Modeled and experimental acoustic velocities in the Gulf Coast natural gas mixture at 540 DEG R.

Gulf Coast Mixture Younglove et al. (1993) 585 DEG R

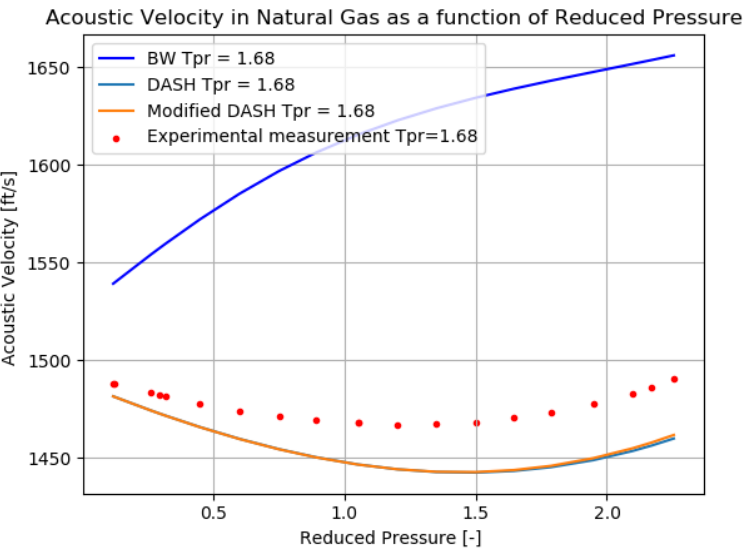

Figure 4 - Modeled and experimental acoustic velocities in the Gulf Coast natural gas mixture at 585 DEG R. 
Gulf Coast Mixture Younglove et al. (1993) 630 DEG R

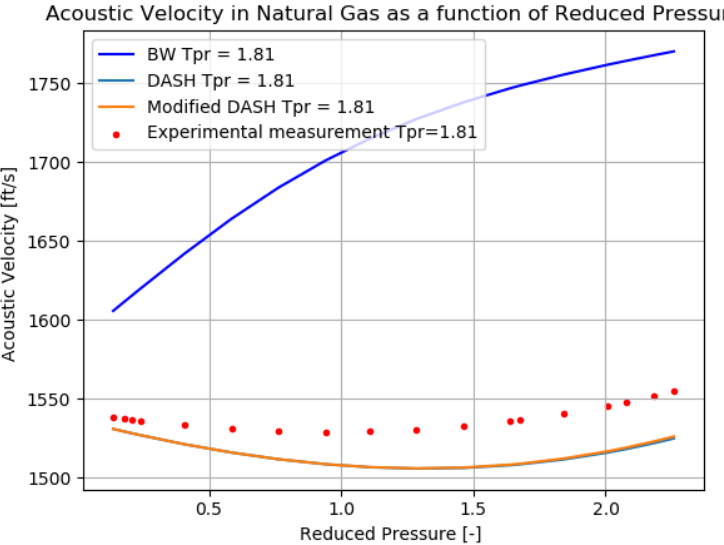

Figure 5 - Modeled and experimental acoustic velocities in the Gulf Coast natural gas mixture at 630 DEG R.

Figures $6-9$ correspond to the modeled acoustic velocity for the Equinor (formerly Statoil) Starvodgass natural gas mixture, at temperatures from 540 DEG R to 630 DEG R. In this heavier mixture, DASH formulation also outperforms BW formulation.

A feature similarly observed for the Stavordgass mixture is that BW formulation tends to yield a higher misfit as pressure and temperature increase. This is an indicator that the BW equations might not be the best approach for modeling seismic velocities of natural gases in scenarios of high pressure and high temperature, once DASH and modified DASH equations provide more accurate modeled results in those cases.

Moreover, the same pattern is observed for modified DASH formulation when compared to the results for the Gulf Coast gas mixture: modified DASH is able to better predict acoustic velocity at lower temperatures, near the critical conditions. This indicates that the modified DASH formulation is capable of capturing a specific temperature dependency.

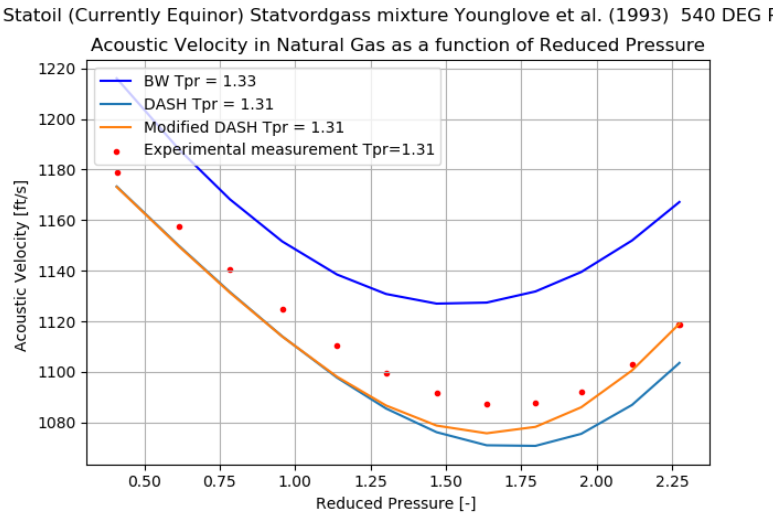

Figure 6 - Modeled and experimental acoustic velocities in the Equinor Starvodgass natural gas mixture at 540 DEG $R$.
Statoil (Currently Equinor) Statvordgass mixture Younglove et al. (1993) 585 DEG R

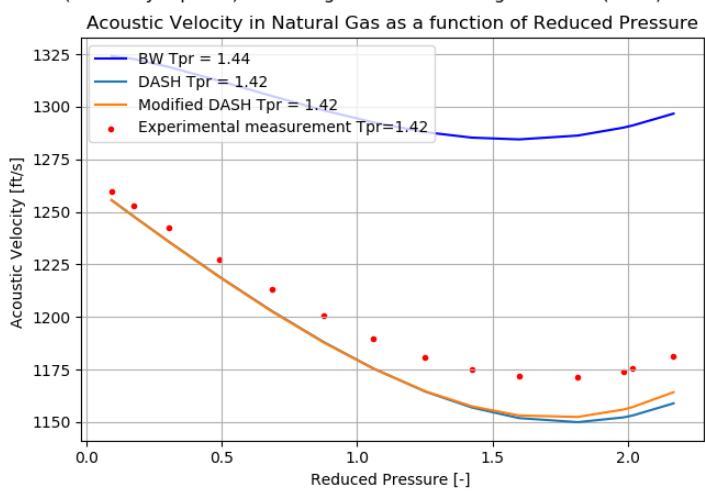

Figure 7-Modeled and experimental acoustic velocities in the Equinor Starvodgass natural gas mixture at 585 DEG $R$.

Statoil (Currently Equinor) Statvordgass mixture Younglove et al. (1993) 630 DEG R

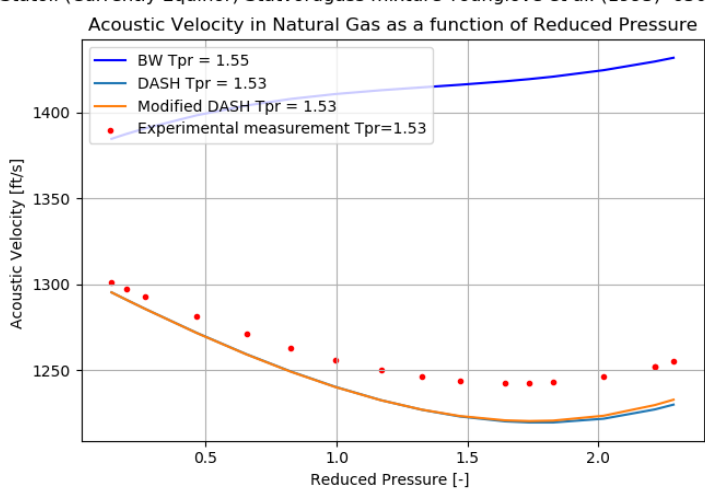

Figure 8-Modeled and experimental acoustic velocities in the Equinor Starvodgass natural gas mixture at 630 $D E G R$.

Figures 9 and 10 demonstrate the difference in AVO response in a modeled case in which fluid properties are calculated with BW and DASH formulations. A larger difference in reflectivity can be observed at the longer offsets.

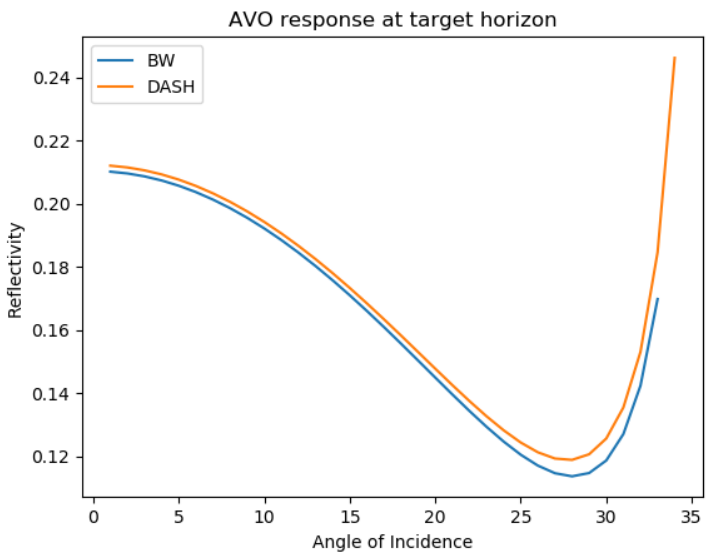

Figure 9-AVO response for fluid properties calculated with BW and DASH formulations for the the Equinor Starvodgass natural gas mixture at a temperature of 126.85 DEG C 


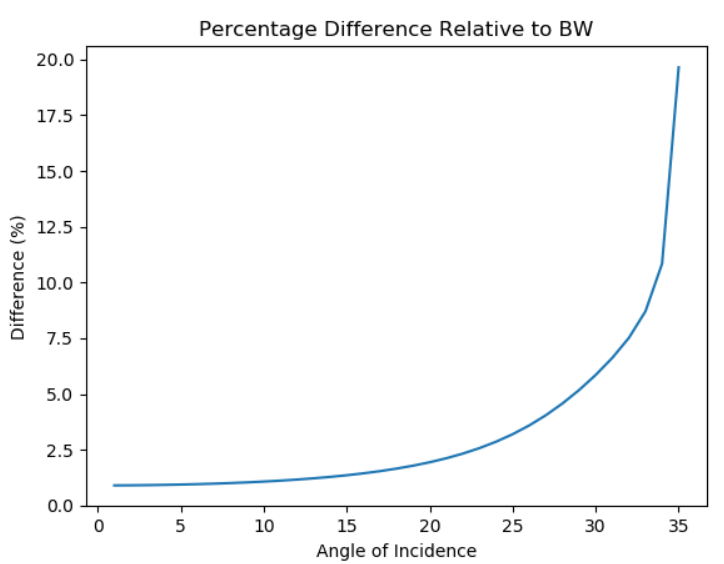

Figure 10 - Variation in reflectivity in the case from Figure 9.

\section{Conclusions}

The results presented indicate that both DASH and modified DASH formulations provide much higher accuracy for modeling the experimental data from the Gulf Coast and the Stavordgass natural gas mixtures. The BW formulation, however, yields the larger misfit in its prediction of acoustic velocity for the fluids studied.

Specifically, the BW equations seem to provide higher misfit as pressure and temperature increase, which could become a point of concern for its applicability in high pressure and high temperature scenarios, such as those found in the Brazilian pre-salt.

Moreover, modified DASH formulation demonstrates to be capable of capturing a temperature bias that the original DASH formulation is not. Therefore, modified DASH appears to provide the best fitting to the experimental data of the two mixtures studied.

Finally, the AVO modeling demonstrates that the use of DASH formulation for computing fluid properties does impact the estimated reflectivity, causing the greater differences at the longer offsets.

Further developments of current work include a sensibility analysis of DASH and modified DASH formulations in order to verify their performance in AVO modeling.

\section{Acknowledgments}

We would like to thank Petrobras for supporting this work, through the scholarship program PRH-PB 226 and research project agreement \# 5850.0108361.18.9. This study has been also, in part, financed by the Coordenação de Aperfeiçoamento de Pessoal de Nível Superior (CAPES), trough its graduate school support program, and by Conselho Nacional de Desenvolvimento Científico e Tecnológico $(\mathrm{CNPq})$, trough the Instituto Nacional de Ciência e Tecnologia Geofísica do Petróleo (INCT-GP).

\section{References}

BATZLE, M. \& WANG, Z. 1992. Seismic properties of pore fluids. Geophysics, 57(11), 1396-1408.

CARVALHO, R. R. \& MORAES, F. S. 2018. Evaluation of an Alternative Formulation for Computing Seismic Properties of Hydrocarbon Fluids. In 80th EAGE Conference and Exhibition 2018.

CARVALHO, R., MORAES, F. \& FREITAS, U. 2018b. AVO analysis using an alternative formulation for estimation of seismic properties of hydrocarbon fluids: a study on gas condensate. In SEG Technical Program Expanded Abstracts 2018 (pp. 664-668). Society of Exploration Geophysicists.

CARVALHO, R. R. \& MORAES, F. S. 2019. An application of Bayesian Inversion for predicting nonhydrocarbon mole fractions in a natural gas mixture. In 80th EAGE Conference and Exhibition 2019.

DRANCHUK, P.M. \& ABOU-KASSEM, J.H. 1975. Calculation of $Z$ Factors For Natural Gases Using Equations of State. The Journal of Canadian Petroleum Technology, 14(3), 34-36.

GASSMANN, F. 1951. Über die elastizität poröser medien: Vier. der Natur. Gesellschaft Zürich, 96, 1-23.

GREGORY, A. R. 1976. Fluid saturation effects on dynamic elastic properties of sedimentary rocks. Geophysics, 41(5), 895-921.

SUTTON, R.P. \& HAMMAN, J.G. 2009. Accuracy of Fluid Property Estimates for Calculating Seismic Properties. SPE Annual Technical Conference and Exhibition, SPE 124971.

YOUNGLOVE, B.A., FREDERICK, N.V. \& MCCARTY, R.D. 1993. Speed of Sound Data and Related Models for Mixtures of Natural Gas Constituents. NIST Monograph 178. National Institute of Standards and Technology, Boulder.

ZOEPPRITZ, K. 1919. VIlb. Über Reflexion und Durchgang seismischer Wellen durch Unstetigkeitsflächen., VIlb. On reflection and transmission of seismic waves by surfaces of discontinuity. 